\title{
EDUCAÇÃO A DISTÂNCIA, EQUIPE DE PRODUÇÃO E INFORMAÇÃO: UMA PROPOSTA EM DEBATE
}

Claudia Silveira da Cunha | claudiasdacunha@gmail.com

Mestre em Educação pela Universidade de Framingham - Massachusetts e Universidade de Brasília (UnB). Doutoranda em Ciência da Informação pela Universidade Federal de Minas Gerais - UFMG.

Alcenir Soares dos Reis | alcenirsoares@gmail.com Doutora em Educação pela Universidade Federal de Minas Gerais (UFMG). Professora do Programa de Pós-Graduação em Ciência da Informação da Universidade Federal de Minas Gerais - UFMG.

\section{Resumo}

Discute-se, a partir do processo de formação acadêmica e da experiência de trabalho na modalidade Educação a Distância (EAD), a importância de incorporar, na equipe de produção de material educativo a dimensão informacional, com o objetivo de trazer à discussão a importância da interação e da contribuição entre a EAD $e$ a Ciência da Informação (CI). Destaca-se que a ausência das dimensões de seleção, organização, tratamento e disseminação da informação, atividades intrínsecas dos profissionais da informação (bibliotecários, cientistas da informação) atuam como variáveis intervenientes e limitadoras tanto na produção do material didático quanto na efetividade do processo de ensino-aprendizagem, no âmbito desse processo educacional. Discutem-se as contribuições $e$ as potencialidades de incorporação de fundamentos e técnicas informacionais que poderão advir da área da Ciência da Informação, tanto no trabalho da equipe de produção quanto nas orientações de aprendizagem destinadas ao corpo discente participante.

\section{Palavras-chave}

Educação a Distância.

Ciência da Informação.

Técnicas informacionais. 


\section{Online tutoring, production team and} information: A proposal in debate.

\section{Abstract}

This article discusses the importance of including the Informational dimension in teams produce educational material for Distance Education ("DE"), throughout the process of academic training and work experience for $\mathrm{DE}$, in order to highlight the interaction and contribution between the Distance Education (DE) and Information Science ("IS"). It demonstrates that the absences of selection processes, organization, processing and dissemination of information, intrinsic activities of information professionals (librarians, information scientists), all act as limiting and defining factors in both the production of educational materials, as well as the effectiveness of the teaching and learning process in this educational process. The article also discusses the potential contribution of incorporating techniques stemming from the study of Information Science ("IS") both in the work of production teams creating material for $\mathrm{DE}$ as well as in the learning guidelines for $\mathrm{DE}$ students.

\section{Keywords}

Distance education. Information science. Information techniques.

\section{La educación a distancia, equipo de producción y de la información: una propuesta para el debate.}

\section{Resumen}

Se plantea, a partir del proceso de formación académica y de la experiencia de trabajo en la modalidad de educación a la distancia, la importancia de incorporarse, en los grupos de producción de material educativo para la Educación a Distancia (EAD), la dimensión informacional, con el objetivo de evidenciar la interacción y la contribución entre la Educación a Distancia (EAD) y la Ciencia de la información (CI). Se destaca que la ausencia de las dimensiones de selección, organización, tratamiento y diseminación de la información, actividades intrínsecas de los profesionales de la información (bibliotecarios, científicos de la información) actúan como variables intervinientes y limitadoras, tanto en la producción del material didáctico como en la efectividad del proceso de enseñanza-aprendizaje, en el ámbito de este proceso educacional. Se enfatizan las contribuciones y las potencialidades de incorporación de fundamentos y técnicas informacionales que podrán advenir del área de la Biblioteconomía y Ciencia de la Información, tanto en el trabajo de los grupos como en las orientaciones de aprendizaje destinadas al cuerpo discente, participante de la formación a la distancia.

\section{Palabras clave}

Educación a distancia. Ciencia de la información. Técnicas informacionales.

\section{Introdução}

Este artigo, de caráter teórico, sistematiza parte do trabalho referente à tese que está sendo desenvolvida na área de Ciência da Informação, cuja proposta é apreender o papel dos profissionais da informação (bibliotecários e cientistas da Informação) no contexto das equipes de produção de material educacional, em diferentes suportes, para a modalidade educação a distância (EAD), com o objetivo de responder à questão da pesquisa.

As motivações para a referida pesquisa advêm das discussões no campo da Biblioteconomia $e$ da Ciência da Informação (CI), bem como de nossas experiências na área de educação a distância (EAD), fatos que nos levaram a eleger como questão a ser pesquisada o papel e a importância da inclusão dos profissionais da citada área nas equipes de produção em EAD. Esta proposta justifica-se em razão das especificidades das atividades que são realizadas por tais profissionais em termos de seleção, organização, tratamento $e$ disseminação da informação. Em razão desses as- 
pectos, pareceu-nos pertinente avaliar as atividades $e$ as dimensões informacionais que se fazem presentes no contexto das equipes de produção para $\mathrm{EAD}$, funções que, acreditamos, permitemlhes contribuir no processo educativo.

É oportuno destacar que, inegavelmente, a informação sempre esteve presente ao longo da história humana, ganhando feições e características distintas no contexto de cada sociedade. Entretanto, há no momento atual um aspecto que lhe confere distinção em relação aos modelos sociais precedentes, haja vista constituir-se a informação como dimensão central nos processos de produção, além de se fazer presente em aspectos históricos, políticos e sociais. Todos esses elementos permitem designar esse modelo social com a denominação de sociedade da informação e do conhecimento.

É necessário, ainda, acrescentar que nesse novo modelo de sociedade alia-se também outro elemento central: a expressividade da tecnologia, que, por suas potencialidades, rompe com os limites de tempo e de espaço, o que torna possível viabilizar, no plano concreto, que a informação se constitua como um dos instrumentos para a inclusão e a cidadania.

Em relação ao âmbito educacional, a tecnologia tem transformado processos e práticas tradicionais da educação e da socialização do conhecimento mediante inovações e mudanças nas formas de produção, representação $e$ interpretação da informação e do conhecimento. Na realidade, as tecnologias estão presentes em nosso cotidiano não apenas sob a forma de suporte, mas intrinsecamente, como cultura, ampliando nossa visão de mundo, modificando as linguagens e propondo novas formas de apreender a realidade. Houve, nos últimos anos do século $\mathrm{XX}$, aumento de propostas educativas sustentadas no modelo da educação a distância e com a utilização crescente de tecnologias para oferecer aos sujeitos do ato educativo um modelo de gestão centrado na comunicação e na aprendizagem.

Somando-se aos aspectos antecedentes e dentro da perspectiva de reconhecimento da prerrogativa de que o acesso à informação é um direito do indivíduo, torna-se importante o provimento de meios e condições para a efetivação desse acesso. Esses fatos fundamentam nossa visão sobre a necessidade de se identificarem funções, papéis e contribuições passíveis de se realizarem pelos profissionais da informação no âmbito da equipe de produção em EAD, de forma a identificar as possibilidades de atuação destes nos aspectos de produção, organização e disseminação da informação na $\mathrm{EAD}$, de forma a contribuir na efetividade dessa modalidade educativa.

Assim, em relação à questão informacional problematizada a partir das funções de seleção, organização, tratamento e disseminação da informação - e sua inserção no contexto da produção de conteúdos para $\mathrm{EAD}$, optamos por orientar a pesquisa no sentido de caracterizar as funções $e$ as atividades que são realizadas na equipe de produção, bem como as que são exercidas pelos profissionais da informação nas dimensões de seu trabalho ( $1^{\text {a }}$ fase dos procedimentos metodológicos), a fim de buscar responder à indagação motivadora da pesquisa.

Portanto, a fim de tornar explícito o percurso já realizado na efetividade da pesquisa, definimos por apresentar este texto de acordo com a seguinte estrutura: a) Justificativa e objetivos; b) Fundamentação teórica; c) Procedimentos metodológicos; d) Conclusões/ Perspectivas.

\section{Justificativa e objetivos}

As experiências e vivências no contexto da EAD e nossa formação na área de Ciência da Informação permitiram formular as indagações objeto desta proposta de pesquisa. Destaca-se ainda, no âmbito da EAD, o trabalho de coordenação de equipes de produção, de criação e desenvolvimento de ambientes a distância, de produção/ autoria de conteúdo de cursos, disciplinas e materiais didáticos, impressos e para web, bem como de objetos de aprendizagem destinados às instituições de ensino (universidades públicas e bra- 
sileiras). Somam-se a estes também os trabalhos realizados para órgãos do governo e corporações e o exercício de tutoria das disciplinas ofertadas para cursos a distância .

Há ainda a acrescentar às atividades anteriores, as realizadas como docente (estágio docente $e$ professor substituto) cujo foco era à interlocução entre Biblioteconomia, Ciência da Informação e Educação a Distância, que permitiram sinalizar a importância do papel da informação nessa modalidade educativa, notadamente através dos cursos lecionados para os graduandos em Biblioteconomia, destacando-se as disciplinas Biblioteconomia, Ciência da Informação e Educação a Distância, Metodologia para Desenvolvimento de Aprendizagem para a Formação do Profissional da Ciência da Informação (CI), Organização da informação: aspectos teóricos, bem como o seminário: Bibliotecários em equipes de EAD.

Vale ainda acrescentar que a experiência docente, aliada às discussões teóricas, tendo como base Lafuente López (1999), Garduño Vera (1999, 2004), Filatro (2004), Reis (2007), Rodrigues (2001), Rodríguez Gallardo (2001), Estabel e Moro (2006, 2007), Cunha e Souza (2006), Santarosa (2006) e Walter (2005), evidenciou a ausência de uma nítida percepção dos graduandos e profissionais da informação em relação à modalidade de EAD como campo potencial de atuação.

É oportuno ainda acrescentar que a experiência, no contexto das equipes de produção de $\mathrm{EAD}$, permitiu observar que elas mantêm suas responsabilidades tradicionais - facilitar, mediar e transformar - os conteúdos destinados à EAD. No exercício dessas funções, identificam-se presentes nas equipes o conteudista/professor-autor, o instrucional pedagógico e o instrucional web. A função do profissional conteudista é selecionar, elaborar e ser responsável pelo conteúdo de qualidade da disciplina a ser oferecida a distância.

Ao instrucional pedagógico, função importante na equipe de produção, mas que nem sempre se encontra presente nas equipes, compete transpor o conteúdo produzido pelo professor-autor para uma linguagem apropriada para o ambiente de EAD e atender às necessidades dos usuários a distância usando pouco ou nenhum contato face a face. Esse profissional deve levar em consideração as expectativas de múltiplas e distintas audiências e avaliar o processo de ensino-aprendizagem articulado às atividades, tarefas, procedimentos pedagógicos e recursos educativos.

A função do instrucional web é criar, definir a arte final e inserir o conteúdo nos modelos e padrões preestabelecidos pela equipe de EAD, após receber o material validado pelo instrucional pedagógico. Em termos globais, pela própria exigência do trabalho, é preciso que as equipes estejam constantemente atualizadas e possuam domínio de modernas ferramentas tecnológicas, sem perder o foco do ensino.

Assim, em decorrência do processo de formação acadêmica, das leituras teóricas, notadamente da área de Biblioteconomia e Ciência da Informação, e da experiência de trabalho em EAD, tornou-se pertinente eleger como questão de estudo e eixo da pesquisa as funções e o papel dos profissionais da informação no contexto da equipe de produção e estabelecer a interlocução entre a Ciência da Informação e a Educação a Distância.

\section{Fundamentação teórica}

\subsection{A Biblioteconomia e a Ciência da Informação: o papel do profissional da informação na organização do conhecimento}

Em termos históricos e de forma sintética, a análise referente ao desenvolvimento da sociedade revela que sempre se constituiu como preocupação dos homens marcar sua trajetória e experiência, haja vista a existência de registros da história humana em diferentes suportes, condição que permitiu que os elementos do passado permanecessem, viabilizando, portanto, pela manutenção da memória, a relação passado-presente.

Tendo como fundamento as análises de Fonseca (1992), Burke (2003), Ortega y Gasset (2007) e Silveira (2007), resgata-se em termos históricos 
que o campo da informação tem como cerne as funções de selecionar, organizar, tratar e disseminar a informação, que são específicas de bibliotecários e cientistas da informação. Ressalva-se, porém, que há etapas precedentes às funções que hoje são realizadas por estes profissionais, uma vez que, do ponto de vista histórico, a sociedade foi se constituindo, o que lhe confere marcas distintas em seus diferentes momentos.

Nesse percurso identificamos um primeiro momento com o domínio da oralidade; um segundo momento, com a instituição da escrita; e um terceiro com a imprensa, situação que dá notória agilidade à comunicação. Assim, pode-se apontar que a tecnologia da escrita e, posteriormente, da imprensa permitiu maior alcance das mensagens discursivas. No momento atual, identificado como Era Digital, produz-se uma mudança radical no armazenamento, na disponibilização e na disseminação da informação, o que facilita e potencializa a incorporação de novos sujeitos ao processo de informação.

Prosseguindo nessa sistematização e tendo como base as discussões de Castells (1999), Kumar (1997), Cepik (2000), Dupas (2001), Werthein (2000) e Dantas (2002), vamos encontrar nas análises desses autores a indicação de que a explosão informacional provocada pelas inovações tecnológicas do século XX, evidenciadas a partir da Segunda Guerra Mundial, fez a quantidade de documentos vigentes no mundo ganhar dimensões incomensuráveis. Os problemas resultantes dessa explosão estão, de modo geral, diretamente ligados à impossibilidade de controle de produção, recuperação, reconhecimento, tratamento e disponibilização contextualizada de conteúdos inseridos nos diferentes suportes.

A cada dia, inumeráveis textos, nascidos nos mais diferentes meios, são concebidos e divulgados por meio dos canais tecnológicos de transmissão de dados, fato que termina por se apresentar com dimensão paradoxal, ou seja, uma proliferação que traz problemas, mas que também representa soluções, pois permite incorporar $e$ incluir novos sujeitos na sociedade da informação.

Ainda no contexto de adoção das técnicas de organização da informação e suas ações, apoiadas na intensificação do uso de tecnologias, inicialmente pelas tecnologias impressas, observa-se, na transmissão da informação, o impacto de uma velocidade na vida cotidiana nunca antes experimentada pela sociedade ao longo da história, implicando a proliferação de acervos - livros, fitas, CDs, DVDs - e, consequentemente, necessidade mais complexa de organizar e acessar a informação.

A quantidade e a complexidade de informação - e dos sistemas e serviços que a proveem - cresceram em consonância com o aumento das necessidades de informação dos cidadãos e de sua dependência desse provimento. O profissional da Biblioteconomia e da Ciência da Informação (CI), especificamente o bibliotecário, aparece então como um intermediário entre as fontes e sistemas de informação e os usuários e se constitui num ator-chave na sociedade da informação. No que se refere ao espaço de atuação profissional, profundamente afetado pelo ambiente tecnológico nos últimos anos, surgiram profundas modificações na forma de atuar - no tratamento, na organização e na disseminação da informação - aliada à necessidade de formação e educação profissional continuada.

Para Guimarães (1997, 2000, 2004), Souza (2002, 2006), Mueller (1989, 2000), Cunha (2000a, 2000b, 2000c, 2002, 2003, 2006), Targino (1997, 2000), Castro (2000), Bohn (1999) e Ferreira (2003), há muita discussão, hoje, sobre as atribuições e responsabilidades relacionadas com os dados, as informações e o conhecimento na sociedade, o que justifica ter como objeto de estudo o profissional da informação.

De forma sintética, uma análise das diferentes formulações indica que, apesar da especificidade e da distinção conferida por diversos autores à definição sobre o profissional da informação, tais profissionais são confrontados com os seguintes fatos: a globalização e a regionalização estão cada 
vez mais presentes; as novas tecnologias abrem possibilidades amplas de prestação de novos serviços; a informação apresenta-se como a força motora do novo modelo econômico, em substituição à energia. Nesse contexto, amplia-se a necessidade de captar, filtrar, tratar, recuperar, distribuir, disseminar informações, e o usuário passa a requerer um tipo de informação filtrada e analisada em detalhes.

Portanto, considerando a realidade descrita, fica patente que novos desafios vêm se colocando aos profissionais da informação, bem como a abertura de novos campos de atuação, dentre os quais se inclui o espaço da Educação a Distância.

É preciso ainda destacar que, em razão dessas exigências impostas ao profissional, ele se depara com os desafios que emergem no novo contexto e que, de certa forma, precisam ser considerados para a formação e para o "fazer" da profissão. É nesse espaço que surge, com maior impacto, a necessidade de compreender as dimensões e ações realizadas na área. Não que velhas rotinas, antigos trabalhos efetuados em bibliotecas tenham de ser eliminados, mas o trabalho desse profissional está sendo desafiado a cumprir e responder às exigências de novos papéis advindos com os processos tecnológicos.

Como afirma Ferreira (2003, p. 48),

o mercado reconhece a necessidade e o valor da informação, a necessidade de habilidades e competências para trabalhar com a informação, a interdisciplinaridade do processo de gestão do conhecimento, identificando as funções para desenvolver essa prática, mas não percebe que essas funções são específicas da Ciência da Informação (FERREIRA, 2003, p. 48).

$\mathrm{Na}$ Era da Informação e da multiplicidade de sua produção, compete aos profissionais, no exercício de suas atividades, selecionar a informação, ou seja, realizar uma "filtragem" de documentos (nos mais variados formatos), em consonância com as necessidades dos usuários; organizar e descrever os documentos, tanto do ponto de vista físico (características físicas dos documentos) quanto do ponto de vista temático (ou de des- crição do conteúdo), resultando na produção de representações documentais (fichas de catálogo, referências bibliográficas, resumos, termos de indexação etc.) realizadas por meio das técnicas de classificação, indexação ou descrição e resumo; propiciar a disseminação da informação.

Assim, pela experiência vivenciada em processos de educação a distância e da pesquisa em andamento, busca-se captar as dimensões e ações informacionais previstas para as funções do profissional da informação e como elas se apresentam no contexto da prática da equipe de produção em EAD. Em razão desses aspectos orientadores, tornou-se relevante explicitar, neste trabalho, o que estamos considerando dimensões informacionais. Vejamos:

dimensões informacionais: compreendidos como os procedimentos teórico-metodológicos selecionar, organizar, tratar e disseminar a informação - oriundos da Biblioteconomia, que viabilizam apreender e organizar o conhecimento.

Inegavelmente, os profissionais são confrontados com uma informação de caráter veloz e versátil, com a potencialidade dos mais variados recursos tecnológicos. Nesse contexto, é possível inferir que eles são essenciais ao efetivo funcionamento das organizações do conhecimento, na medida em que podem contribuir para a construção de um desenho de EAD que se torne cada vez mais dinamizador da educação nacional. Vale destacar que a simples migração de materiais desenvolvidos em outras linguagens, sem a devida adaptação para a modalidade EAD, implica consequências danosas ao processo de ensino-aprendizagem, situação que se apresenta ainda como um problema e desafio para as equipes de produção.

\subsection{A Educação e seus diversos níveis e modalidades}

A educação, em seus diversos níveis e modalidades, é uma área privilegiada para compreender e prever os processos que são gerados com a constante aparição de tecnologias e seus respectivos desafios, transformando os processos e práti- 
cas tradicionais da educação e da socialização do conhecimento. Essas inovações são acompanhadas de uma reestruturação sem precedentes nos modos de produção e consumo na esfera educacional; consequentemente, nos processos de formação humana. Atualmente, a mediação dos processos culturais requer um sujeito com maior competência crítica, habilidade e rapidez não só no acesso às informações, mas na sua seleção $e$, sobretudo, na reelaboração dos conhecimentos.

Em relação à educação, percebe-se uma mudança na abordagem do "educar". Segundo Cardoso (2002), a função educativa hoje

visa não mais a transmissão de conteúdos, e sim a formação de sujeitos cognitivos com competências e habilidades para enfrentar situações inesperadas, solucionar problemas inéditos, acompanhar o desenvolvimento do conhecimento em suas áreas de interesse e respeitar a pluralidade cultural planetária (2002, p. 3).

Segundo Paulo Freire, (citado por BARRETO, 2003, p. 61), "a educação pode contribuir para que as pessoas se acomodem ao mundo em que vivem ou se envolvam na transformação dele".

Para abordar a modalidade educação a distância em uma perspectiva de mudança, faz-se necessário retomar, de forma sucinta, alguns elementos do pensamento de Freire, num esforço inicial de compreender as transformações e o papel da educação nesse processo. A leitura de Freire (2004) tem possibilitado, de um lado, fundamentar as produções teórico-acadêmicas que compõem o universo das discussões sobre as temáticas da educação e, de outro, refletir criticamente acerca das práticas educativas e pedagógicas, principalmente aquelas que se apresentam no horizonte das mudanças.

Agregando ao que foi afirmado por Freire, Rodrigues (2001) assegura que

a Educação, entendida como processo de formação humana, atua sobre os meios para a reprodução da vida - e essa é sua dimensão mais visível e prática -, bem como coopera para estender a aptidão do homem para olhar, perceber e compreender as coisas, para se reconhecer na percepção do outro, constituir sua própria identidade, distinguir as semelhanças $e$ diferenças entre si e o mundo das coisas, entre si e outros sujeitos. A Educação envolve todo esse instrumental de formas de percepção do mundo, de comunicação e de intercomunicação, de autoconhecimento e de conhecimento das necessidades humanas. E propõe-se a prover as formas de superação dessas necessidades, sejam elas materiais ou psíquicas, de superação ou de reconhecimento de limites, de expansão do prazer e outras (RODRIGUES, 2001, p. 243).

Em continuidade, complementa:

Educar requer o preparo eficiente dos educandos para que se capacitem, intelectual e materialmente, para acionar, julgar e usufruir esse complexo de experiências com o mundo da vida. Esta é uma responsabilidade a ser atribuída ao educador (RODRIGUES, 2001, p. 243).

Para Freire (2004, p. 15), "quando o homem compreende sua realidade, pode levantar hipóteses sobre o desafio dessa realidade e procurar soluções. Assim, pode transformá-la e com seu trabalho pode criar um mundo próprio".

Embora os processos de educação a distância existam há um tempo significativo, o desenvolvimento de novas tecnologias de informação $e$ comunicação (TICs) proporcionaram, mais recentemente, novo impulso a essa modalidade/estratégia de ensino. Para muitos ela representa uma alternativa que permitirá enfrentar a influência da globalização e a constante aparição e uso de tecnologias na prestação de serviços educativos.

Segundo Reis et al. (2007), a modalidade EAD ganha nova dimensão no contexto atual, como resultado das possibilidades advindas com as tecnologias de informação e comunicação, à medida que não se constituem como restrições a dispersão geográfica, as limitações físicas, as condições e os diferentes ritmos de aprendizagem dos participantes do processo.

No seu sentido corrente, observa Gatti (2005),

educar e educar-se a distância requer condições muito diferentes da escolarização presencial. Os alunos em processos de educação a distância não contam com a presença cotidiana e continuada de professores nem com o contato constante com 
seus colegas. Embora possam lidar com os temas de estudo disponibilizados em diferentes suportes, no tempo e no local mais adequados para seus estudos, num ritmo mais pessoal, isso exige determinação, perseverança, novos hábitos de estudo, novas atitudes em face da aprendizagem, novas maneiras de lidar com suas dificuldades (GATTI, 2005, p. 143).

Em síntese, pensar o processo educativo tendo como referência a educação a distância implica compreender que as dificuldades e os obstáculos são de outra ordem, diferentemente do modelo presencial, o que exige pensar que os desafios para a EAD requerem múltiplas habilidades e parcerias para seu êxito.

\subsection{As Tecnologias de Informação e Comunicação (TICs) e a educação a distância (EAD)}

Atualmente, a educação a distância, com as potencialidades das Tecnologias de Informação e Comunicação (TICs), tende a fomentar o estudo independente e grupal, a interação acadêmica entre os atores da aprendizagem e a utilização de diversos canais de comunicação, entre os quais predomina a internet. Nessa concepção, a EAD está em busca das condições de produção do conhecimento e de uma perene e processual marca construcionista. O objetivo é colocar realmente o aluno como centro do processo, considerando os valores agregados à socialização $e$ à democratização do conhecimento, tendo em vista a importância da informação, da cultura e da tecnologia nas práticas educativas, visando um ensino crítico, formador de indivíduos autônomos, capazes de atuar em redes.

A comunicação educativa, a interação e o diálogo acadêmico constituem a base sobre a qual se sustenta o êxito ou o fracasso de toda proposta educativa a distância. Entretanto, a introdução de novas tecnologias não implica necessariamente novas práticas pedagógicas, pois podemos com ela apenas vestir o "velho" com uma "roupagem nova", conforme observado nos livros eletrônicos, tutoriais multimídia e alguns cursos a distância disponíveis na internet, que não incorporam nada de novo no processo de construção de materiais e na concepção do processo de ensino-aprendizagem.

Dessa forma, as novas tecnologias são usadas apenas como instrumento (PRETTO, 1996), o que tende a ser inócuo na educação, se não repensarmos os demais elementos envolvidos nesse processo. Nesses termos, "sua utilização acaba por resultar quase sempre em aulas em vídeo iguais às da escola de hoje ou a textos em microcomputadores interativos e autoinstrutivos mais limitados que os livros existentes nas estantes escolares" (KAWAMURA, 1998).

Sabe-se, entretanto, que os meios, por si só, não são capazes de trazer contribuições para a área educacional e que eles são ineficientes se usados como o ingrediente mais importante do processo educativo ou sem a reflexão humana. Mesmo aqueles que defendem a tecnologia, proclamando apenas seus benefícios, devem considerar que a Tecnologia de Informação e Comunicação (TIC) deve adequar-se às necessidades de determinado projeto político-pedagógico, colocando-se a serviço de seus objetivos - e nunca os determinando.

A adoção das Tecnologias de Informação e Comunicação (TICs), embora traga contribuições para a EAD, não implica que os recursos humanos especializados e competentes desapareçam ou diminuam. A despeito dos desvios e contradições, na maioria das profissões provocados pela informatização, e dos recursos que ela oferece na implementação de novas estratégias de ação profissional, ela representa um instrumento novo tanto para as profissões de perfil tecnológico quanto do biológico e do social, podendo otimizar processos ou serviços, facilitar combinações de informações, agilizar respostas, mas não podendo necessariamente mudar a base epistemológica de um campo de conhecimento.

Segundo Catapan e Fialho (2001), incorpora-se ainda aos aspectos antecedentes,

que o mundo da comunicação digitalizada formaliza-se com maior agilidade, pois se sustenta na codificação da informação 
e na comunicação da mensagem por diferentes formas de linguagem. A educação, por sua vez, não prescinde da informação e do processo de comunicação, mas se diferencia destes pelo objetivo de potencializar a construção conceitual, a partir da interpretação da informação e da reelaboração da mensagem, isto é, pelo compromisso com a construção de novos conhecimentos (CATAPAN e FIALHO, 2001, p. 2).

Entretanto, acreditar que novas práticas pedagógicas implicam o uso de novas tecnologias, confiando à tecnologia a renovação da educação, seria uma visão extremamente tecnicista do processo educativo. Na realidade, não é possível pensar em práticas pedagógicas e nas tecnologias dissociadamente, e sim como importantes elementos do processo de ensino-aprendizagem que devem basear-se em novas concepções de conhecimento, nas dimensões informacionais e, especialmente, no que se refere à produção de materiais para a modalidade educação a distância.

\subsection{A produção de material didático em EAD: problemas e desafios}

O processo de produção de materiais é fundamental para o desenvolvimento de cursos na modalidade $\mathrm{EAD}$, principalmente porque, diferentemente do ensino presencial, o professor não está vendo o que o aluno está fazendo nem se está motivado. Dessa forma, utilizar os recursos para despertar a atenção e desafiar o aluno é essencial para o sucesso na implantação da modalidade.

$\mathrm{Na}$ educação a distância, essas funções devem ser assumidas pelos profissionais envolvidos no processo e pelo material instrucional. O tratamento do material para a educação a distância requer uma equipe de produção composta por coordenador de produção, professor-autor/conteudista, instrucional web, instrucional pedagógico, programadores, revisores, profissionais da comunicação e especialistas em TI no uso das plataformas de gerenciamento. Essa equipe se encarrega da produção dos materiais, sendo capaz de efetivar as seguintes ações: criar os modelos instrucionais dos ambientes de aprendizagem, definir a interface gráfica do projeto; adaptar e transpor o conteúdo curricular articulado a procedimentos $e$ atividades pedagógicas, dentro de um modelo definido pela instituição; identificar os objetivos referentes às competências cognitivas, habilidades e atitudes; validar a bibliografia, videografia, iconografia, audiografia, tanto básicas quanto complementares, apresentadas pelo autor; elaborar e avaliar o material didático antes e depois de ser impresso, videogravado, audiogravado, indicando correções e aperfeiçoamentos; autoavaliar-se continuamente como profissional participante do coletivo de um projeto na modalidade a distância.

Cada equipe possui características próprias, de dimensões multidisciplinares; portanto, necessita trabalhar para a sedimentação do projeto do curso, estabelecendo um fluxo de trabalho e ações bem definido para sua efetividade. Entretanto, uma equipe por si só não se justifica e nem se sustenta isoladamente. O funcionamento de cada uma fica permanentemente atrelado a uma dinâmica na qual um conjunto de ações, específicas ou não, depende do funcionamento adequado de todos, ou seja, o cumprimento normal do trabalho de uma equipe compromete a qualidade e o funcionamento de outra e vice-versa. É necessário, pois, interação, troca de experiências, diálogo permanente para a consolidação das metas propostas pelo programa.

Somando-se aos aspectos aqui apontados, é preciso que o perfil de cada agente da equipe seja definido claramente para que seja possível viabilizar a realização do projeto. Por isso, cada membro da equipe precisa desempenhar seu papel no processo de produção; cada um deles exige diferentes competências, que resultarão em produtos próprios.

Nesse contexto, Pfromm Netto (1998) destaca que

Toda a vastíssima gama de materiais e equipamentos audiovisuais mobilizados para educar depende, para produzir resultados que se traduzam em efetivo aprendizado, de boa qualidade e duradouro, de uma combinação ótima do trabalho sinergético de profissionais com diferentes competências: 
(a) profissionais que dominem os múltiplos processos e meios técnico-artísticos necessários ao planejamento e à produção de materiais educativos - diretores, produtores, roteiristas, operadores de câmara, operadores de áudio, engenheiros de som, cenógrafos, iluminadores etc.; (b) especialistas responsáveis pela qualidade do conteúdo a ser ensinado/aprendido; (c) especialistas que se incubam da orientação psicopedagógica da produção, segundo os princípios e as regras originados $d a$ pesquisa sobre como os seres humanos aprendem, retêm e aplicam o que aprenderam (PFROMM NETTO, 1998).

A transferência da teoria para a prática na produção de materiais para EAD não é fácil nem óbvia. Em termos efetivos, a consulta à literatura sobre equipes de produção na EAD, aos autores que advogam sobre design instrucional e nossa experiência como coordenadoras de produção evidenciam que a estruturação do conteúdo na modalidade EAD está diretamente vinculada à equipe de produção, revelando alguns problemas que merecem ser objeto de reflexão. Dentre estes destacam-se: a profusão de falsos conceitos tratados como axiomas; imagens que se, em tese, deveriam dar suporte ao texto, nada têm a ver com eles; animações gratuitas que competem com o conteúdo tratado por ser fonte de distração; fontes que, se belas para títulos, tornam-se ilegíveis em parágrafos longos; textos cujas cores, ao invés de harmonizar com o fundo, contrastam ou se misturam com este; materiais em sequência linear marcante na apresentação de conteúdo (texto, imagem e som), sob uma falsa crença de que essa ainda é a melhor maneira de apresentar o conteúdo - não considerando que, atualmente, com todos os recursos tecnológicos, na modalidade $\mathrm{EAD}$, imagem e som têm maior impacto no processo ensino-aprendizagem que o texto.

Percebe-se, ainda, a falta de incorporação de especialistas em EAD na equipe de produção, o que faz com que eventualmente haja busca de ajuda a profissionais com perfil de comunicação, o que provoca, regra geral, a utilização de uma linguagem não apropriada ao processo de ensino-aprendizagem remoto, com uma produção inadequada à EAD.
Cabe ressaltar que, para a produção de materiais para EAD, não se pode prescindir de ter uma equipe multidisciplinar. É possível aventar que, mediante os estudos e reflexões aqui apresentados, as potencialidades de incorporação de fundamentos e técnicas informacionais advindos da área da Biblioteconomia e da Ciência da Informação podem trazer ganhos e contribuições para a modalidade de EAD.

\section{Procedimentos metodológicos}

Tendo em vista a constituição da proposta da pesquisa, cujo objetivo é analisar a incorporação do profissional da informação no contexto da equipe de $\mathrm{EAD}$ e estabelecer a interlocução entre Ciência da Informação e Educação a Distância, tornou-se necessário definir um percurso metodológico que permitisse identificar esses elementos $e$ que eles fornecessem o arcabouço para caracterizar a importância dos profissionais da informação no âmbito da EAD. Assim, para viabilizar esses objetivos, implementamos estas ações: $1^{\text {a }}$ Fase de acordo com a seguinte dinâmica:

a) Levantamento bibliográfico e sistematização teórica relativa às discussões da área de Biblioteconomia, Ciência da Informação e Educação a Distância, consolidando os principais aspectos que distinguem o trabalho dos profissionais da informação, as questões centrais que se encontram presentes no processo de educação na modalidade EAD, bem como o efetivo mapeamento dos diferentes aspectos relativos à estrutura organizacional naquela modalidade. Essa atividade tornou possível categorizar a estruturação da EAD em três âmbitos: 1) Projeto pedagógico, que compreende a instituição, o processo pedagógico e o desenho conceitual do curso (coordenador do curso, coordenador pedagógico da EAD, acompanhamento pedagógico e/ou didático); 2) Equipe de produção, que abrange o coordenador de produção, o conteudista, também conhecido como professor-autor, o instrucional pedagógico, o instrucional web, o ilustrador e o revisor; 3) Equipe de acompanhamento do aluno, que envolve o tutor e o 
docente; 4) Elementos de apoio e suporte, que compreendem a monitoria, os especialistas em Tecnologia da Informação e Comunicação (TICs) e a secretaria;

b) Sistematização e consolidação, em quadros-síntese, do perfil das diferentes funções presentes na estrutura organizacional da equipe de EAD, ação que permitiu identificar e caracterizar os processos e elementos constituintes das atividades dos atores e compreender que não se pode fazer mera transposição do modelo presencial para o modelo a distância;

c) Identificação e mapeamento da situação da EAD no Brasil, em termos de instituições e cursos vigentes, o que nos permitiu identificar a existência de 97 instituições autorizadas a oferecer cursos em EAD (entre públicas e privadas), nas quais são ofertados 118 cursos tecnológicos, 108 cursos de bacharelado e 169 cursos de licenciatura, distribuídos pelas regiões brasileiras (dados de coleta de fev/2009). Em etapa subsequente da pesquisa, faremos o levantamento da existência das equipes de produção e de como elas se constituem;

d) Elaboração e sistematização referente ao desenvolvimento histórico da área de Biblioteconomia e Ciência da Informação, assim como caracterização e descrição das funções e técnicas do trabalho do profissional da informação em termos de seleção, organização, tratamento e disseminação da informação;

e) Produção e elaboração de quadros-síntese que evidenciam as especificidades e características das funções dos profissionais da informação $e$ aquelas exercidas pelos integrantes da equipe de produção. $\mathrm{Na} 2^{\mathrm{a}}$ Fase da pesquisa (em andamento) será feita avaliação e contraposição entre os dois universos, a fim de identificar se há espaço de atuação para o profissional da informação na equipe de produção e o seu papel nesse contexto.

\section{Conclusões/Perspectivas}

Considerando os fundamentos que subsidiam este trabalho, que tem como eixo apreender o pa- pel do profissional da informação no contexto da equipe de produção de EAD, optamos por orientá-lo a partir da perspectiva de que os problemas, as dificuldades e os desafios que se apresentam na EAD decorrem do fato de não serem consideradas as dimensionais informacionais.

Concretamente, com base na literatura da $\mathrm{Bi}$ blioteconomia, Educação e Ciência da Informação, é possível assinalar que a dimensão da informação e sua incorporação no trabalho conjunto com a equipe de produção podem se constituir como um aporte importante para a produção de material de EAD.

A ausência de discussão em relação à dimensão informacional, pensada no contexto deste trabalho com a utilização dos aportes da Biblioteconomia e da Ciência da Informação, termina por produzir um ruído no processo entre o pensar EAD (conceber) e a execução (equipe de produção). Dentro desta perspectiva, ressalta-se que os aspectos informacionais sejam adotados, de forma que eles nos permitam a elaboração de categorias passíveis de integrar um modelo orientado para o processo de produção em equipes de EAD.

De acordo com Bohn (1999), os serviços que a sociedade demanda do profissional da Informação têm tomado diferentes direções, devido às necessidades criadas pelas mudanças sociais, culturais e tecnológicas. Essa situação coloca os profissionais da Informação não só em competição com especialistas de outras áreas como, naturalmente, direciona as áreas da profissão por novos caminhos e exige do profissional um elenco mais amplo de conhecimentos e competências.

Portanto, é possível inferir que, em razão das potencialidades e do domínio das ações de organização, tratamento, recuperação e disseminação da informação específicos dos profissionais da área, sua contribuição poderá se efetivar pela seleção e filtragem do material, pelo refinamento qualitativo das informações necessárias ao processo educativo, pela organização e pela disponibilização do conteúdo, pelo gerenciamento e manutenção do acervo físico e virtual, assim como 
no processo de disseminação.

Dessa forma, colocam-se como desafios para a modalidade de EAD a ampliação dos participantes nas equipes de produção, com a incorporação dos profissionais da informação, e que se realize a formação para aqueles docentes que passam a integrar a educação a distância, com vistas a romper visões equivocadas de que esse processo de formação é fácil e simples, sem necessidade de preparação específica para aqueles que a integram.

A necessidade de integrar e desenvolver a modalidade educação a distância como uma alter- nativa capaz de contribuir para a solução dos problemas históricos presentes de forma recorrente na educação brasileira permite vislumbrar as contribuições da Biblioteconomia e da Ciência da Informação no âmbito da EAD, bem como inserir a modalidade EAD como objeto de estudo e pesquisa no campo da informação.

Em síntese, cremos que esta pesquisa poderá representar uma contribuição para as áreas e esclarecer e apontar alternativas e caminhos para maior interlocução entre a Biblioteconomia, a Ciência da Informação e a Educação a Distância.

\section{Referências bibliográficas}

BARRETO, Vera. Paulo Freire para Educadores. São Paulo: Arte \& Ciência, 2003.

BOHN, Maria del Carmen R. O ensino da área de controle sob a perspectiva da competência: experiência no curso de Biblioteconomia da UFSC. Encontros Bibli: Revista Eletrônica de Biblioteconomia e Ciência da Informação, Florianópolis, n. 8, 1999. Disponível em: http://www.encontros-bibli.ufsc.br/ sumario.htm. Acesso em: 05/08/2005.

BURKE, Peter. Uma história social do conhecimento: de Gutenberg a Diderot. Rio de Janeiro: Jorge Zahar, 2003.

CARDOSO, Ana Maria Pereira. Educação para a Informação: desafios contemporâneos para a Ciência da Informação. DataGramaZero - Revista de Ciência da Informação, v. 3, n. 5, out./02,artigo 06. Disponível em: http://www.dgz.org.br/out02/F_I_art.htm. Acesso em: 21/07/2007.

CASTELLS, Manuel. A sociedade em rede. $2^{\mathrm{a}}$ ed. São Paulo: Paz e Terra, 1999. v. 1.

CASTRO, César Augusto. Profissional da Informação: perfis e atitudes desejadas. Inf. \& Soc.: Est., João Pessoa, v. 10, n. 1, p. 142-156, 2000.

CATAPAN, Araci Hack e FIALHO, Francisco Antonio Pereira. Pedagogia e tecnologia: a comunicação digital no processo pedagógico. Disponível em: http://www.abed.org.br/congresso2001/40.doc. Acesso em: 03/01/2011.

CEPIK, Marco. Direito à informação: situação legal e desafios. IP. Informática Pública, Belo Horizonte, v. 2, n. 2, p. 43-56, 2000. Disponível em http://www.ip.pbh.gov.br/ANO2_N2_PDF/ip0202cepik.pdf. Acesso em: 05/02/2007.

CUNHA, Miriam Vieira da. A formação dos profissionais da Informação na França: comparação com o sistema brasileiro. In: VALENTIM, Marta Lígia Pomim (Org.). O profissional da Informação: formação, perfil e atuação profissional. São Paulo: Polisv,11, cap. 3, p. 71-90, 2000a. (Coleção Palavra-Chave). . O profissional da Informação: formação e mercado de trabalho. Revisão de literatura. Ensaios APB, São Paulo, n. 82-84, 2000 b.

. O profissional da Informação e o mercado de trabalho. Informação \& Sociedade: Estudos, João Pessoa, v. 10, n. 1, p. 159-167, jan./jun.2000c.

. O papel social do bibliotecário. Enc. Bibli: R. Eletr. Bibliotecon. Ci. Inf., Florianópolis, n. 15, 
$1^{\circ}$ sem. 2003. Disponível em: http://www.encontros-bibli.ufsc.br/regular.html. Acesso em: 11/11/2007.

As profissões e as suas transformações na sociedade. In: CUNHA, Miriam Vieira; SOUZA, Francisco das Chagas (Org.). Comunicação, gestão e profissão: abordagens para o estudo da Ciência da Informação. Belo Horizonte: Autêntica, 2006.

CUNHA, Miriam Vieira da; SILVA, E. L. A formação profissional no século XXI: desafios e dilemas. Ciência da Informação, Brasília, v. 31, n. 3, p. 77-82, set./dez. 2002.

CUNHA, Miriam Vieira; SOUZA, Francisco das Chagas (Org.). Comunicação, gestão e profissão: abordagens para o estudo da Ciência da Informação. Belo Horizonte: Autêntica, 2006.176p.

DANTAS, Marcos. A lógica do capital-informação: a fragmentação dos monopólios e a monopolização dos fragmentos num mundo de comunicações globais. $2^{a}$ ed. Rio de Janeiro: Contraponto, 2002.268p. DUPAS, Gilberto. Ética e poder na sociedade da Informação: de como a autonomia das novas tecnologias obriga a rever o mito do progresso. $2^{a}$ ed. São Paulo: Ed. Unesp, 2001.

ESTABEL, Lizandra Brasil; MORO, Eliane Lourdes da Silva. Capacitação de bibliotecários com limitação visual pela educação a distância em ambientes virtuais de aprendizagem. Ci. Inf., Brasília, v. 35, n. 3, p. 209-217, set./dez. 2006.

A formação profissional e a educação a distância mediada por computador: uma experiência no curso de Biblioteconomia do DCI/FABICO/UFRGS. Inf. \& Soc.: Est., João Pessoa, v. 17, n. 2, p. 97-107, maio/ago.2007.

FERREIRA, Danielle Thiago. Profissional da Informação: perfil de habilidades demandadas pelo mercado de trabalho. Ciência da Informação, v. 32, n. 1, p. 42-49, jan/abr. 2003.

FILATRO, Andrea. Design instrucional contextualizado: educação e tecnologia. São Paulo: Editora Senac São Paulo, 2004.

FONSECA, Edson Nery da. Introdução à Biblioteconomia. São Paulo: Pioneira, 1992.

FREIRE, Ana Maria Araújo. Pedagogia dos sonhos possíveis. São Paulo: Ed. Unesp, 2001.

FREIRE, Paulo. Educação e mudança. 27ª ed.. Rio de Janeiro: Paz e Terra, 2004.

GARDUÑO VERA, Roberto. Internet en la educación virtual: un enfoque desde la investigación y la enseñanza en Bibliotecología. Investigación Bibliotecológica, México, v. 18, n. 36, p. 42-74, enero/ junio. 2004.

GATTI, Bernadete A. Critérios de qualidade. In: ALMEIDA, Maria Elizabeth B.; MORAN, José Manuel (Org.). Integração das tecnologias na educação. Secretaria de Educação a Distância. Brasília: Ministério da Educação, SEED, 2005. 204p.

GUIMARÃES, José Augusto Chaves. Moderno profissional da informação: elementos para sua formação no Brasil. Transinformação, Campinas, v. 9, n. 1, p. 124-137, jan./abr. 1997.

. O profissional da Informação sob o prisma de sua formação. In: VALENTIM, Marta Lígia Pomim (Org.). O profissional da Informação: formação, perfil e atuação profissional. São Paulo: Polis, v. 11, cap. 2, p. 53-70, 2000. (Coleção Palavra-Chave).

. Profissionais da Informação: desafios e perspectivas para sua formação. In: BAPTISTA, Sofia Galvão; MUELLER, Suzana Pinheiro Machado (Orgs.) Profissional da Informação: o espaço de trabalho. Brasília: Thesaurus/CID-UnB, p. 87-104, 2004.

KAWAMURA, Regina. Linguagem e novas tecnologias. In: ALMEIDA, Maria José P. M. de; SILVA, Henrique César da (Orgs.). Linguagens, leituras e ensino da ciência. Campinas: Mercado das Letras, 1998. KUMAR, K. Da sociedade pós-industrial à pós-moderna: novas teorias sobre o mundo contemporâneo. Rio de Janeiro: Jorge Zahar, 1997.

LAFUENTE LÓPEZ, Ramiro; GARDUÑO VERA, Roberto. Enseñanza a distancia de la Bibliotecología 
y estudios de la Información. Investigación Bibliotecológica, México, v. 13, n. 27, p. 153-179, jul./dic, 1999.

MUELLER, Suzana Pinheiro Machado. Perfil do bibliotecário, serviços e responsabilidades na área de Informação e formação profissional. Revista de Biblioteconomia de Brasília, v. 17, n. 1, p. 63-70, jan./ jun. 1989.

Universidade e Informação: a biblioteca universitária e os programas de educação a distância - uma questão ainda não resolvida. DataGramaZero - Revista de Ciência da Informação, v. 1 , n. 4, ago. 00. Disponível em: http://www.dgz.org.br/ago00/Art_01.htm. Acesso em 07/12/2007.

ORTEGA Y GASSET, José. Misión del bibliotecário. Disponível em: http://www.cddhcu.gob.mx/bibliot/ publica/libros/mision/indiceco.htm. Acesso em: 06/10/2007.

PFROMM NETTO, Samuel. Telas que ensinam - mídia e aprendizagem: do cinema ao computador. Campinas: Alínea, 1998.

PRETTO, Nelson. Uma escola sem/com futuro - educação e multimídia. Campinas: Papirus, 1996.

REIS, Alcenir S. dos; RIBAS, Claudia S. da Cunha; PEDROSO, Ana Paula F. Novas tecnologias de comunicação no processo de educação a distância: possibilidades, limites e desafios. Revista de Economía Política de las Tecnologías de la Información y Comunicación, v. IX, n. 1, p. 1- 18, jan./abr./2007. Disponível em: http://www2.eptic.com.br/eptic_es/interna.php?c=82\&ct=397\&o=1. Acesso em: 29/11/2007.

RODRIGUES, Neidson. Educação: da formação humana à construção do sujeito ético. Educação \& Sociedade, ano XXII, n. 76, p. 232-257, out. 2001.

RODRÍGUEZ GALLARDO, José Adolfo. Formación humanística del bibliotecólogo: hacia su recuperación. México: UNAM, CUIB, 2001. 284p.

SANTAROSA, Lucila Maria Costi; ESTABEL, Lizandra Brasil; MORO, Eliane Lourdes da Silva. BIBLIOTEC II: o bibliotecário como mediador propiciando a inclusão informacional, social, educacional $e$ digital através da EAD. Inf. \& Soc.: Est., João Pessoa, v. 16, n. 2, p. 127-141, jul./dez. 2006.

SILVEIRA, Fabrício José Nascimento da. Biblioteca como lugar de práticas culturais [manuscrito]: uma discussão a partir dos currículos de Biblioteconomia no Brasil. 2007. Dissertação (mestrado em Ciência da Informação). Escola de Ciência da Informação, Universidade Federal de Minas Gerais, Belo Horizonte, 2007.

SOUZA, Francisco das Chagas de. Pesquisa em educação bibliotecária e novas DCN (Diretrizes Curriculares Nacionais) do curso de Biblioteconomia no Brasil. Inf. \& Soc.: Est., João Pessoa, v. 12, n. 2, p. 230-249, jul./dez. 2002. Disponível em: http://periodicos.ufpb.br/ojs2/index.php/ies/issue/view/18/ showToc. Acesso: 10/11/2007.

A formação acadêmica de bibliotecários e cientistas da Informação e sua visibilidade, identidade e reconhecimento social no Brasil. Inf. \& Soc.: Est., João Pessoa, v. 16, n. 1, p. 32-46, jan./jun. 2006.

TARGINO, Maria das Graças. Práxis bibliotecária. Inf. \& Soc.: Est., João Pessoa, v. 7, n. 1, p. 3949,1997. Disponível em: http://periodicos.ufpb.br/ojs2/index.php/ies/article/viewFile/352/274. Acesso em: $11 / 11 / 2007$.

. Quem é o profissional da Informação. Transinformação, Campinas, v. 12, n. 2, p. 61-69, jul./dez. 2000.

VILAN FILHO, Jayme Leiro. Hipertexto: visão geral de uma nova tecnologia da informação. Ci. Inf. Brasília, v. 23, n. 3, p. 295-308, set./ dez.1994.

WALTER, Maria Tereza Machado Teles. A formação do profissional da Informação relacionada às tec- 
nologias de Informação: os bibliotecários na perspectiva da literatura, reflexões. Enc. Bibli: R. Eletr. Bibliotecon. Ci. Inf., Florianópolis, n. 19, p. 1-20,1º sem. 2005.

WERTHEIN, Jorge. A sociedade da informação e seus desafios. Ci. Inf., Brasília, v. 29, n. 2, p. 71-77, maio/ago. 2000. 